\title{
Someone is not listening to the facts: there is little psychiatry outside child and adolescent psychiatry
}

\author{
Celso Arango
}

Published online: 2 August 2012

(C) Springer-Verlag 2012

Given these trying economic times, let us start with some economic evidence. We have recently learned from a study funded by the European College of Neuropsychopharmacology (ECNP) and the European Brain Council (EBC) that brain disorders, and mental disorders in particular, are not only one of the main causes of burden and suffering for European countries, but they cost the EU more than cardiovascular and oncologic disorders combined. The incredible figure of roughly 798 billion euros was the cost of mental disorders to European citizens in 2010 [4]. In theory only 5.2 million correspond to the category of "childhood/adolescent disorders". However this clearly does not reflect the real costs of mental disorders caused by abnormal growth and rearing, abnormal neurodevelopment, or a more distal cause of a later mental disorder in adulthood, i.e. trauma, abuse, neglect, or social exclusion during childhood and adolescence.

New environmental factors affecting brain development as early as in utero that increase the risk of developing a mental disorder later in life (in adolescence or early adulthood) are reported every month. In this issue Atterman et al. (in press) review the available data on how prenatal exposure to hormones may increase the risk of attention-deficit/hyperactivity disorder (ADHD) and autism spectrum disorders (ASD). In their study with an impressive sample size, female twins with a twin brother scored significantly lower in parent-reported traits of ADHD and ASD as compared to those with a twin sister. An intrauterine environment affected by the sex of the co-twin

\section{Arango $(\square)$}

Child and Adolescent Psychiatry Department, Hospital General Universitario Gregorio Marañón, Instituto de Investigación Biomédica Gregorio Marañón, CIBERSAM, Madrid, Spain e-mail: carango@hggm.es could be one of the plausible explanations for this finding. Another article in this issue reflects that some environmental factors, such as sexual abuse, are far more common than expected. Using data from a longitudinal randomised controlled trial of a school-based intervention programme for reducing adolescent sexual assault and related risk behaviours, Brasmen et al. (in press) assessed the prevalence of adolescent peer-on-peer sexual victimisation over a 6-month period. The worrisome percentage of $18.5 \%$ of the 15-year-old females were sexual victims of peers in such a short follow-up period. In the future more research in the interaction between genetic risk factors and early environmental factors is clearly needed. As Van Os [7] recently stated, this is especially relevant for child psychiatry research.

We now know that, although not diagnosed until adulthood, the first symptoms of most mental disorders appear during childhood and adolescence. It has been calculated that up to $70 \%$ of mental disorders have their first symptoms during or before adolescence [3]. Many of these disorders persist throughout the life span. In fact there are very few psychiatric disorders that develop during adulthood that do not have antecedents, at the symptomatic or pathophysiological level, during childhood. How many cases of anxiety disorders has anyone seen that did not have anxiety traits during childhood or adolescence? Even conditions such as schizophrenia and bipolar disorders, traditionally seen as adult psychiatric disorders, are neurodevelopmental disorders. Whether the psychotic or manic symptoms appear at the age of 18,20 or 28 , what causes those symptoms is clearly present during childhood and adolescence, and probably in most cases even in early development in utero. Therefore preventive intervention should take place either prenatally, perinatally or in early childhood, when the brain is more plastic. 
Studies conducted in recent decades have shown that early intervention translates to better outcomes [2]. But the truth is that most of these so-called early interventions are only secondary prevention. If we truly want to go from secondary prevention to primary prevention or to mental health promotion, we need to act much earlier. I believe that the beneficial mental health consequences of healthy pregnancies, better perinatal care and normal early childhood development have not been emphasised enough. The plasticity of the brain is the best ally of the child psychiatrist. Early evidence in the field of autism treatment is a good example of this; interventions that take place at earlier ages seem to be more effective. Recent studies show how intensive treatment that involves the whole family at age 2 or 3 can produce significant improvements in cognitive performance, language skills and adaptive behaviour. In some cases patients no longer met the diagnostic criteria for Autism Spectrum Disorder after 1 year of intensive early intervention $[6,5]$.

Despite these objective facts, with few exceptions such as the recent Australian movement for mental health in young people, the field of child and adolescent psychiatry has never received the attention that it deserves. With psychiatry usually led by adult psychiatrists in most European countries-in fact in countries such as Spain there is no child and adolescent psychiatry specialty-our field has often been neglected or at least not taken as seriously as it should be. It is clear that cost-effective interventions in mental health should be targeted towards the paediatric population. This is clearly not the case at the European level, with most resources devoted to adult psychiatry and tertiary prevention. If we want a future where adults have better mental health, integrated mental health-promoting approaches need to be developed targeting paediatric populations [1].

It is important that any mental health research initiative at the European level consider the relevance of child psychiatry. The European Commission recently decided to fund a project (http://www.roamer-mh.org/) that will lead to a coordinated roadmap for the promotion and integration of mental health and well-being research throughout
Europe, based on a common methodology and conceptual framework that covers the full spectrum of biological, psychological, epidemiological, public health, social and economic aspects of mental health and well-being. Research on normal and abnormal neurodevelopment, costeffective treatments for mental disorders in children and adolescents, well-being in patients at that age, promotion of mental health and prevention of mental disorders in childhood, child neuropsychopharmacology, educational and social aspects of mental health in the paediatric population are just a few examples of areas that need to be prioritised in such a roadmap.

\section{References}

1. Arango C (2011) Physical comorbidity in mental illness in paediatric population: need for an integrated health care approach to paediatrics and child psychiatry. Eur Child Adolesc Psychiatry 20(8):379-380

4. McGorry P (2012) Early intervention in psychiatry: the next developmental stage. Early Interv Psychiatry 6(1):1-2

5. Paus T, Keshavan M, Giedd JN (2008) Why do many psychiatric disorders emerge during adolescence? Nat Rev Neurosci 9(12): 947-957

6. Gustavsson A, Svensson M, Jacobi F, Allgulander C, Alonso J, Beghi E, Dodel R, Ekman M, Faravelli C, Fratiglioni L, Gannon B, Jones DH, Jennum P, Jordanova A, Jönsson L, Karampampa K, Knapp M, Kobelt G, Kurth T, Lieb R, Linde M, Ljungcrantz C, Maercker A, Melin B, Moscarelli M, Musayev A, Norwood F, Preisig M, Pugliatti M, Rehm J, Salvador-Carulla L, Schlehofer B, Simon R, Steinhausen HC, Stovner LJ, Vallat JM, den Bergh PV, van Os J, Vos $\mathrm{P}, \mathrm{Xu} \mathrm{W}$, Wittchen $\mathrm{HU}$, Jönsson B, Olesen $\mathrm{J}$; CDBE2010 Study Group. Cost of disorders of the brain in Europe 2010. Eur Neuropsychopharmacol. 2011;21(10):718-79

7. Itzchak EB, Zachor DA (2009) Change in autism classification with early intervention: predictors and outcomes. Res Autism Spectrum Disord 3:967-976

8. Pellicano E (2012) Do autistic symptoms persist across time? Evidence of substantial change in symptomatology over a 3-year period in cognitively able children with autism. Am J Intellect Dev Disabil 117(2):156-166

9. Van Os J (2012) Solutions for patients depend on whether we can bridge the divide between social and natural science research approaches in the area of mental health. Rev Psiquiatr Salud Ment $05: 135-138$ 